\title{
Surgical Treatment of Carotid-Siphon Aneurysms
}

\author{
Tohru Mitsugi, Haruhiko Kikuchi, Jun Karasawa, \\ Kenjiro ITOH and Nobuaki TAKAHASHI
}

Department of Neurosurgery, National Center of Circulatory Disease, Suita

\begin{abstract}
The direct surgical attack on carotid-siphon aneurysm is hazardous and difficult as compared with other intracranial aneurysms because of its location adjacent to the skull base, the optic nerves and chiasm. The authors report and discuss the surgical treatment of carotid-siphon aneurysms based on our surgical experience of 20 such aneurysms in 18 cases during the period from October 1971 to September 1980.

1. Many aneurysms arising from the $\mathrm{C}_{2}$ carotid-ophthalmic portion of the internal carotid artery can be treated by neck clipping through the pterional approach. It is preferable to clip the neck through a contralateral pterional approach in some cases where the fundus projects posteromedially.

2. For giant aneurysms, it is advisable, along with internal carotid artery trapping, to perform superficial temporal-middle cerebral artery anastomosis.

3. Small aneurysms arising from the $\mathrm{C}_{3}$ or $\mathrm{C}_{4}$ portions of the internal carotid artery will become only faintly visible in angiograms after internal carotid artery ligation with superficial temporal-middle cerebral artery anastomosis, which indicates its effectiveness as a treatment for such aneurysms.
\end{abstract}

Key words: carotid-siphon aneurysm, neck clipping, internal carotid ligation, internal carotid trapping, superficial temporal-middle cerebral artery anastomosis

\section{Introduction}

Many authors agree that the best treatment for intracranial aneurysms is direct surgical attack with neck clipping. But direct surgery on aneurysms arising from the carotid-siphon (carotid-siphon aneurysms) has been considered particularly hazardous and technically difficult because such aneurysms lie on the skull base near the cavernous sinus and are situated close to the optic nerve and chiasm. Therefore, carotid-siphon aneurysms are more problematic than other intracranial aneurysms in regard to the choice of operation, such as neck clipping, internal carotid ligation and trapping. Many reports are available concerning the surgical treatment of carotid-siphon aneurysms, but the results of the direct attack on such aneurysms have been unsatisfactory. The authors report and discuss the surgical treatment of carotid-siphon aneurysms which are classified by their angiografical locations and by the projections of the aneurysmal fundi.

Received December 17, 1981; Accepted February 15, 1982

\section{Clinical Materials and Methods}

Twenty carotid-siphon aneurysms were found among 583 intracranial aneurysms experienced during the period from October 1971 to September 1980. Twenty carotid-siphon aneurysms in 18 cases were treated surgically, and are summarized. All of the cases underwent preoperative bilateral carotid and vertebral angiography whether or not other intracranial aneurysms had previously been found. Most patients were operated in the chronic, not the acute stage of subarachnoid hemorrhage. However, some patients with highly positioned carotid-siphon aneurysms accompanied by other intracranial aneurysms or vascular lesions causing subarachnoid hemorrhage were treated in the acute stage. Neck clipping of the aneurysm was performed, as a rule in the chronic stage. Most of the patients were checked for the quality of collateral blood flow using Matas' test, along with EEG recording or CBF measurement in some of the cases, to determine the feasibility of neck clipping.

First, the cervical internal carotid artery was exposed under general anesthesia. In the case of an aneurysm located in a high position, such as in the neck at $\mathrm{C}_{2}$, the aneurysm was treated through the pterional 
approach. ${ }^{22)}$ The frontal lobe was gently retracted after frontolateral craniotomy. At the parasellar cistern, the anterior clinoid process at the upper roof of the optic nerve was shaved by Hall's air jet drill. The carotid-siphon aneurysm was treated after it had been separated from the optic nerve, the internal carotid artery, and the origin of the ophthalmic artery. Some of the cases of medium-sized aneurysms whose sacs projected posteromedially were amenable to neck clipping from between the bilateral optic nerves via the contralateral pterional approach. Large carotid-siphon aneurysms were treated with internal carotid artery trapping. Small aneurysms which originated in the cavernous portion were treated with internal carotid ligation. In those cases treated with internal carotid trapping or ligation, superficial temporal-middle cerebral artery anastomosis was performed at the same time to prevent cerebral ischemia. Aneurysms whose necks could not be exposed completely and those whose broad neck might cause stenosis of the internal carotid artery when clipped were treated by coating.

\section{Results}

After surgery of the 18 cases; 13 were in excellent condition, 1 was good, 2 were fair, and 2 died. The two cases which had not undergone surgery both died (Table 1): One case died of severe subarachnoid hemorrhage and the other died of hemorrhagic infarction before surgery. The ages were from 21 to 65 years old. There were three times as many famale cases (15) as male (5). Two cases had bilateral carotid-ophthalmic aneurysms and another had cerebral AVM as well. There were 7 cases of subarachnoid hemorrhage. Case 4, who was thought to have bled from another aneurysm, had postoperative angiospasm and developed a slight recent memory disturbance. In Case 6, the hemorrhage was conceivably due to AVM, attributable to an intracerebral hematoma localized in the left temporo-occipital lobe, and was left with slight aphasia and right hemiparesis. Case 17, who had a $_{3}$ aneurysm of anteromedial projection, was treated by neck-clipping. However, return to society was difficult in this case because of CSF-rhinorrhea. Even though Case 9 bled during the operation, the

Table 1 Summary of carotid-siphon aneurysms

\begin{tabular}{|c|c|c|c|c|c|c|c|}
\hline $\begin{array}{l}\text { Case } \\
\text { No. }\end{array}$ & Sex & Age & $\begin{array}{l}\text { Signs \& } \\
\text { Symptoms }\end{array}$ & $\begin{array}{l}\text { Associated } \\
\text { aneurysm } \\
\text { or AVM }\end{array}$ & $\begin{array}{l}\text { Interval to } \\
\text { operation } \\
\text { after SAH }\end{array}$ & Surgery & Results \\
\hline 1 & $\mathbf{M}$ & 35 & headache & none & 39 days & neck clipping & excellent \\
\hline 2 & $\mathbf{F}$ & 21 & headache & none & - & neck clipping & excellent \\
\hline 3 & $\mathrm{~F}$ & 37 & unconsciousness & none & - & none & dead \\
\hline 4 & $\mathbf{M}$ & 40 & headache & $\begin{array}{l}\text { lt. ICPC, rt. ICPC } \\
\text { lt. IC-Ant. chor. }\end{array}$ & 2 days & coating & good \\
\hline 5 & $\mathrm{M}$ & 44 & dementia & none & - & coating & excellent \\
\hline 6 & $\mathbf{M}$ & 38 & $\begin{array}{l}\text { somnolence } \\
\text { headache }\end{array}$ & AVM & 2 months & coating & fair \\
\hline 7 & $\mathbf{F}$ & 21 & headache & none & - & coating & excellent \\
\hline 8 & $\mathbf{F}$ & 65 & diplopia & - & - & $\begin{array}{l}\text { trapping }+\mathrm{ST} \cdot \mathrm{MC} \\
\text { coating }\end{array}$ & excellent \\
\hline 9 & $\mathbf{F}$ & 58 & headache & none & 1 month & trapping $+\mathrm{ST} \cdot \mathbf{M C}$ & dead \\
\hline 10 & $\mathbf{F}$ & 46 & headache & none & 2 years & coating & excellent \\
\hline 11 & $\mathbf{F}$ & 46 & $\begin{array}{l}\text { diplopia } \\
\text { blepharoptosis }\end{array}$ & none & - & trapping $+\mathbf{S T} \cdot \mathbf{M C}$ & excellent \\
\hline 12 & $\mathrm{~F}$ & 32 & diplopia & none & - & ligation $+\mathrm{ST} \cdot \mathrm{MC}$ & excellent \\
\hline 13 & $\mathbf{M}$ & 52 & 1t. hemiparesis & none & - & ligation + ST $\cdot \mathrm{MC}$ & excellent \\
\hline 14 & $\mathrm{~F}$ & 53 & drowsy & none & 7 days & neck clipping & dead \\
\hline 15 & $\mathbf{F}$ & 45 & headache & & 7 months & $\begin{array}{l}\text { neck clipping } \\
\text { neck clipping }\end{array}$ & excellent \\
\hline 16 & $\mathrm{~F}$ & 46 & diplopia & none & - & neck clipping & excellent \\
\hline 17 & $\mathbf{F}$ & 55 & 1t. hemiparesis & none & - & neck clipping & fair \\
\hline 18 & $\mathbf{F}$ & 53 & It. hemiparesis & none & 一 & neck clipping & excellent \\
\hline 19 & $\mathbf{F}$ & 65 & rt. hemiparesis & none & - & none & dead \\
\hline 20 & $\mathbf{F}$ & 50 & vertigo & none & - & trapping $+\mathbf{S T} \cdot \mathbf{M C}$ & excellent \\
\hline
\end{tabular}

trapping $+\mathrm{ST} \cdot \mathrm{MC}: \mathrm{IC}$ trapping with $\mathrm{ST} \cdot \mathrm{MC}$ anastomosis, ligation $\mathrm{ST} \cdot \mathrm{MC}: \mathrm{IC}$ ligation with $\mathrm{ST} \cdot \mathrm{MC}$ anastomosis 
aneurysm was treated with left internal carotid artery trapping and with left superficial temporal-middle cerebral artery anastomosis. This patient died of extensive brain swelling postoperatively. Case 14, who was in the acute stage of subarachnoid hemorrhage, died of angiospasm.

The following is an investigation of the origins of the aneurysms, and projection and size of the fundus. We examine the following methods of treatment: 1) neck-clipping; 2) internal carotid artery ligation or trapping with superficial temporal-middle cerebral artery anastomosis; 3) coating of aneurysm.

\section{Neck clipping}

Eight carotid-siphon aneurysms in 7 cases were treated by neck clipping (Table 2). Five aneurysms were treatable with neck clipping via the ipsilateral pterional approach. Although the aneurysm neck was at the $\mathrm{C}_{3}$ portion of the carotid-siphon in Case 17, who postoperatively developed the complication of CSF-rhinorrhea, the neck was at $\mathrm{C}_{2}$ in all the other cases. Aneurysms whose fundi projected upward or superomedially could be treated with neck clipping by the ipsilateral pterional approach without any damage to the optic nerve or internal carotid artery. Case 14, who had been perfectly treated by clipping, died postoperatively after complications due to angiospasm. Others were able to return to society without neurological deficit after clipping of the aneurysm. Here follow some representative cases. Case 15, a 45-year-old female who had experienced persistent hypertension for five years, visited another hospital on January Ist, 1978 because of severe headache, nausea, and vomiting. She

Table 2 Carotid-siphon aneurysms treated with neck clipping

\begin{tabular}{|c|c|c|c|c|}
\hline $\begin{array}{l}\text { Case } \\
\text { No. }\end{array}$ & $\begin{array}{l}\text { Age } \\
\text { Sex }\end{array}$ & $\begin{array}{l}\text { Origin of } \\
\text { aneurysm }\end{array}$ & $\begin{array}{l}\text { Projection of } \\
\text { fundus }\end{array}$ & Approach \\
\hline 1 & $\begin{array}{l}35 \\
\mathbf{M}\end{array}$ & rt. $C_{2}$ & superior & rt. pterional \\
\hline 2 & $\begin{array}{l}21 \\
\mathrm{~F}\end{array}$ & lt. $\mathrm{C}_{2}$ & supero-medial & lt. pterional \\
\hline 14 & $\begin{array}{l}53 \\
\mathrm{~F}\end{array}$ & rt. $C_{2}$ & superior & rt. pterional \\
\hline 15 & $\stackrel{45}{F}$ & $\begin{array}{l}\text { lt. } C_{2} \\
\text { rt. } C_{2}\end{array}$ & $\begin{array}{l}\text { superior } \\
\text { postero-medial }\end{array}$ & $\begin{array}{l}\text { lt. pterional } \\
\text { lt. pterional* }\end{array}$ \\
\hline 16 & $\begin{array}{c}46 \\
F\end{array}$ & lt. $C_{2}$ & postero-medial & rt. pterional* \\
\hline 17 & $\begin{array}{l}55 \\
\mathrm{~F}\end{array}$ & rt. $C_{3}$ & postero-medial & rt. pterional \\
\hline 18 & $\stackrel{53}{\mathrm{~F}}$ & rt. $C_{2}$ & postero-medial & 1t. pteriona $1^{*}$ \\
\hline
\end{tabular}

*: Neck clipping through contralateral approach

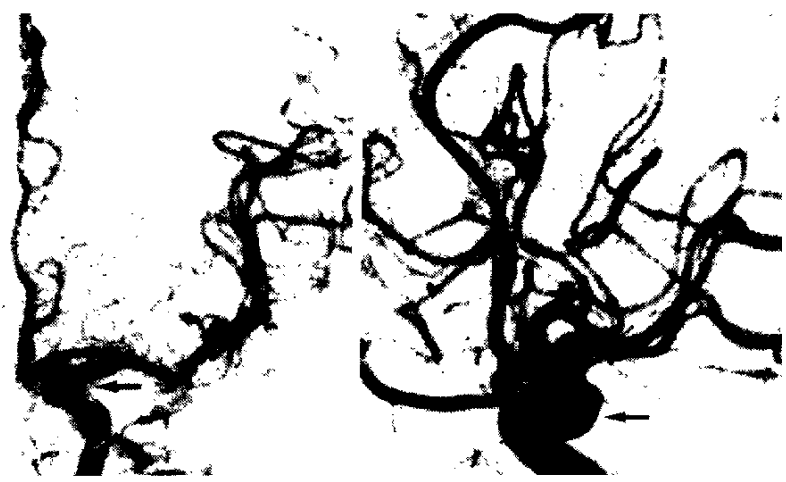

Fig. 1 Case 15; Left carotid angiogram showing a carotid-ophthalmic aneurysm $(\rightarrow)$, with fundus projecting posteromedially. left; frontal view, right; lateral view

was alert. After 3 days she became free from headache and neurological problems. She was introduced to our hospital July 4th, 1978. On her admission, she did not have any neurological deficits. She underwent bilateral carotid and vertebral angiography. The left internal carotid angiogram demonstrated a medium-sized aneurysm projecting superomedially from the $C_{2}$ portion of the left internal carotid artery (Fig. 1). An additional aneurysm, projecting posteromedially and arising from the $\mathrm{C}_{2}$ portion of the right internal carotid artery, was revealed in the right internal carotid angiogram. The crossflow from the right internal carotid artery through the anterior communicating artery was in good condition. Upon performing Matas' test for 20 minutes, no neurological ischemic sign appeared either clinically or in the EEG monitor, such as the appearance of slow waves.

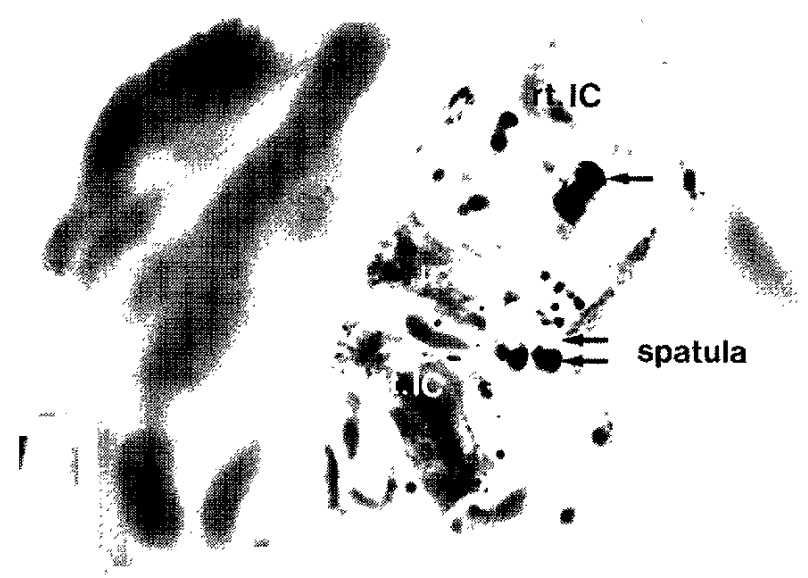

Fig. 2 Case 15; Photograph of operative findings. Two clips applied to right $(\rightarrow)$, and left carotidophthalmic aneurysms $(\rightrightarrows)$ through the left pterional approach. rt.IC; right internal carotid artery, It. IC; left internal carotid artery, lt.II; left optic nerve. 


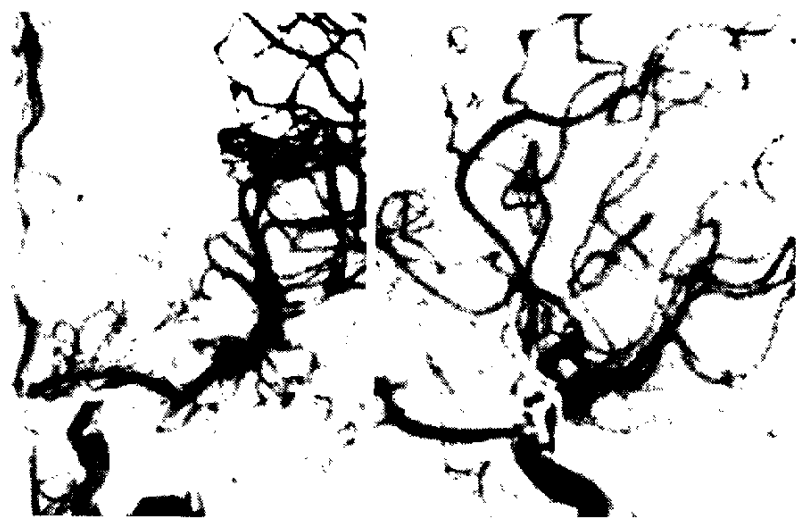

Fig. 3 Case 15; Postoperative left carotid angiogram showing disappearance of aneurysm with clipping.

The aneurysm and the origin of the left ophthalmic artery were dissected and separated through the left pterional approach and the carotid-siphon aneurysm was satisfactorily clipped. The right carotid-siphon aneurysm was clipped from the space between both optic nerves through the left pterional approach (Fig. 2). She developed right upper quadrant anopsia of the right eye. However, after one month she was free from neurological deficit and was discharged from our hospital. In the postoperative angiogram (Fig. 3), the aneurysms were shown to have disappeared.

Case 18, a 53-year-old woman, was admitted on April 2, 1980 because of sudden left-sided hemiparesis. CT scan showed right putaminal hemorrhage. Right carotid angiogram revealed an aneurysm arising from the wall of the right carotid artery, just distal to the opthalmic artery, whose fundus projected posteromedially (Fig. 4). Left frontolateral craniotomy was performed on May 6, 1980 under general anesthesia. The right carotid-siphon aneurysm was exposed and clipped satisfactorily through the space
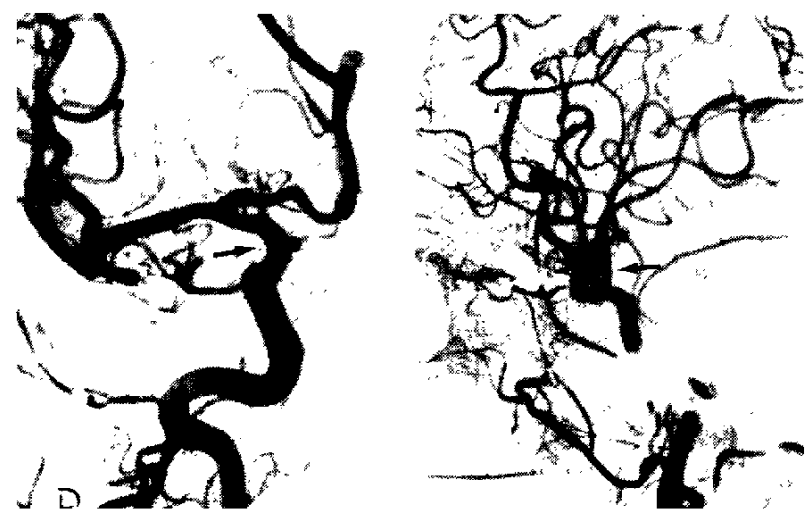

Fig. 4 Case 18; Right carotid angiogram showing a carotid-ophthalmic aneurysm $(\rightarrow)$, with fundus projecting posteromedially.

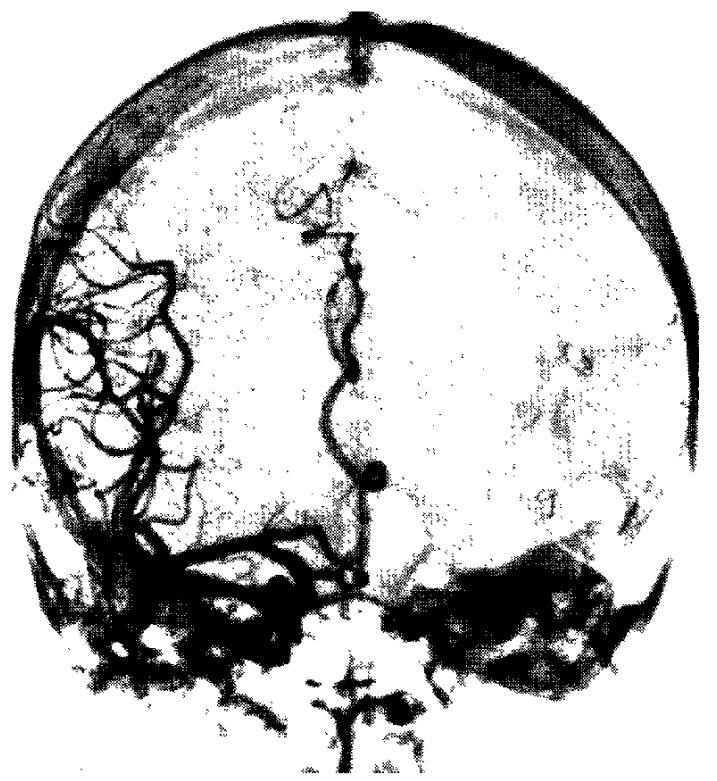

Fig. 5 Case 18; Postoperative right carotid angiogram showing disappearance of aneurysm with clip applied through the contralateral pterional approach.

between the bilateral optic nerves and the tuberculum sellae via the contralateral pterional approach, without sacrificing the internal carotid artery or the optic nerves. The carotid-siphon aneurysm was well clipped and was shown to have disappeared in a postoperative angiogram (Fig. 5). Though a slight left hemiparesis remained, the patient was discharged from the hospital.

\section{Internal carotid artery ligation with superficial temporal-middle cerebral artery anastomosis} Internal carotid artery ligation was performed in two cases with small aneurysms at the cavernous portion or $\mathrm{C}_{4}$ of the internal carotid artery (Table 3 ). Postopera-

Table 3 Carotid-siphon aneurysms treated with IC ligation or trapping with $\mathrm{ST} \cdot \mathrm{MC}$ anastomosis

\begin{tabular}{cccll}
$\begin{array}{c}\text { Case } \\
\text { No. }\end{array}$ & $\begin{array}{c}\text { Age } \\
\text { Sex }\end{array}$ & $\begin{array}{c}\text { Origin of } \\
\text { aneurysm }\end{array}$ & $\begin{array}{c}\text { Projection of } \\
\text { fundus }\end{array}$ & \multicolumn{1}{c}{ Operation } \\
\hline 8 & 65 & rt. $\mathrm{C}_{3}$ & antero-lateral & rt. IC trapping \\
& $\mathrm{F}$ & & & \\
9 & 58 & rt. $\mathrm{C}_{3}$ & anterior & rt. IC trapping \\
& $\mathrm{F}$ & & & \\
11 & 46 & lt. $\mathrm{C}_{3}$ & antero-lateral & It. IC trapping \\
& $\mathrm{F}$ & & & \\
12 & 32 & lt. $\mathrm{C}_{4}$ & anterior & lt. IC ligation \\
& $\mathrm{F}$ & & & rt. IC ligation \\
13 & 54 & rt. $\mathrm{C}_{4}$ & anterior & rt. IC trapping \\
& $\mathrm{M}$ & & lateral & \\
\hline
\end{tabular}


tively, both of them were in excellent condition without neurological deficit. Their postoperative carotid angiograms showed very faint aneurysm. A representative case is demonstrated.

Case 12, a 32-year-old female, was referred to

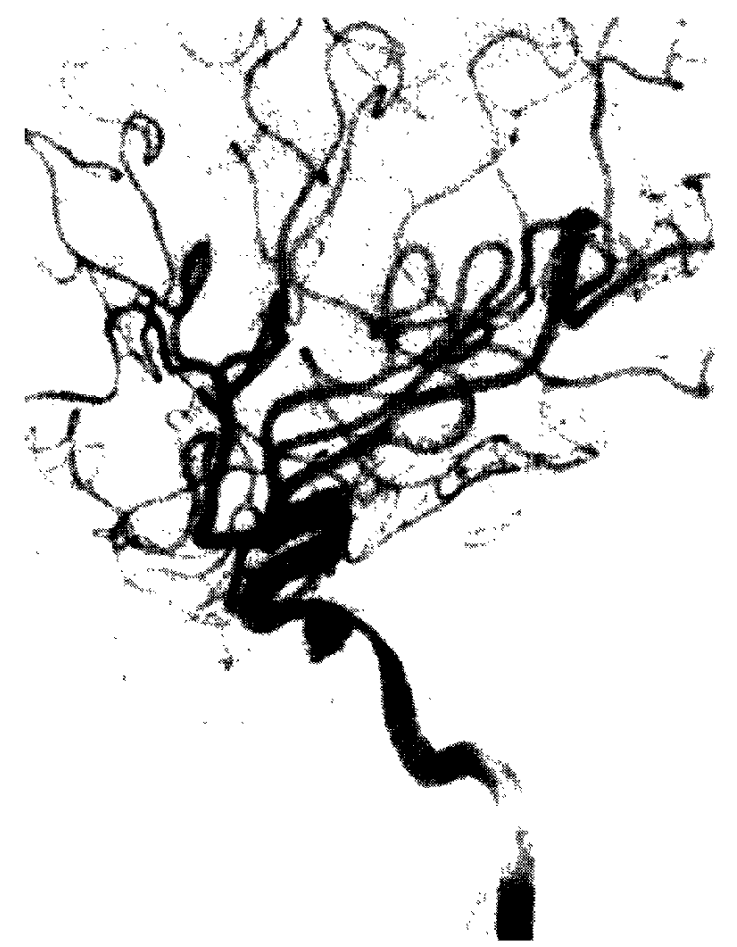

Fig. 6 Case 12; Left carotid angiogram showing an aneurysm arising from the cavernous portion, with fundus projecting inferiorly.

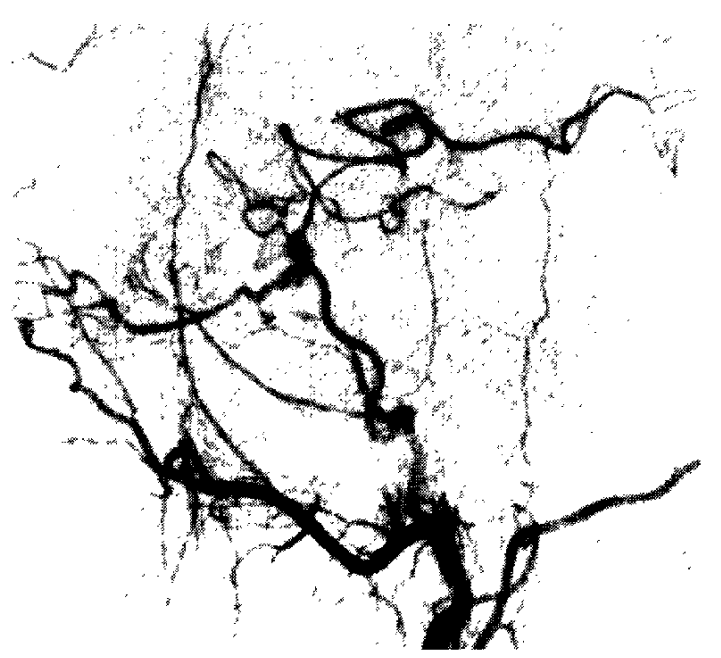

Fig. 7 Case 7; Postoperative carotid angiogram showing faint aneurysm and patent $\mathrm{ST} \cdot \mathrm{MC}$ anastomosis, and carotid-siphon filled via the ophthalmic artery. our hospital for double vision over the previous two years. Left abducens paresis was noted on her admission, but the other cranial nerves were intact. A carotid aneurysm at the cavernous portion was revealed in the left carotid angiogram (Fig. 6). Matas' test and an EEG were performed; which failed to demonstrate signs of cerebral ischemia. Left carotid ligation and superficial temporal-middle cerebral artery anastomosis were performed. A postoperative left carotid angiogram revealed a faint carotid aneurysm, and showed the cortical branches of the middle cerebral artery to be well-filled via the anastomosed superficial temporal artery (Fig. 7). After the operation, the abducens paresis showed a slight improvement, and the patient was discharged from our hospital without neurological deficit.

\section{Internal carotid artery trapping with superficial temporal-middle cerebral artery anastomosis}

Four comparatively large carotid-siphon aneurysms with necks at $\mathrm{C}_{2}$ or $\mathrm{C}_{3}$ were treated with this method (Table 3). This method was applied in these cases because complete exposure of the aneurysmal necks was not possible due to large size, even though the aneurysms were at high positions. In Case 9, the aneurysm ruptured during the operation and the patient died postoperatively of marked brain swelling. However, the other cases have returned to society.

Case 8, a 65-year-old female, visited our hospital on February 1, 1975, after suffering from right oculomotor nerve paresis for the previous three months. The patient complained of right blepharoptosis and diplopia, and right oculomotor paresis was noted upon admission. Other neurological deficits were not found. Right carotid angiogram revealed an aneurysm which projected anterolaterally, arising from the internal carotid artery at the origin of the ophthalmic

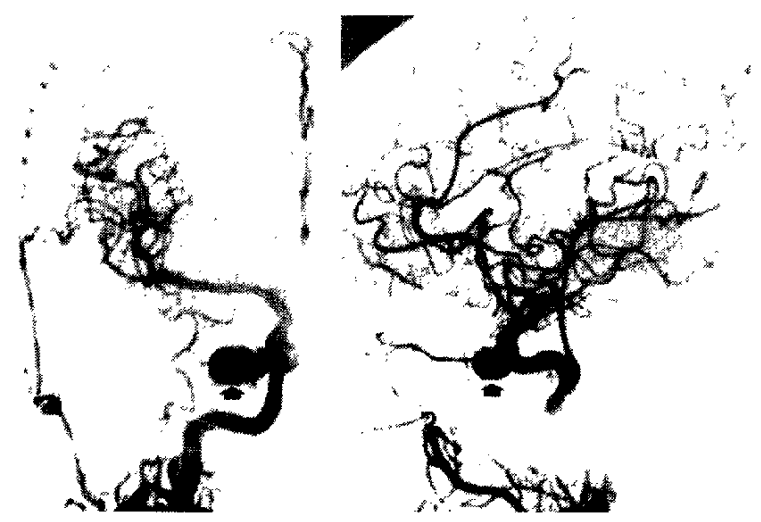

Fig. 8 Case 8; Right carotid angiogram showing a comparatively large aneurysm $(\rightarrow)$ arising from $C_{3}$, with fundus projecting anterolaterally. 


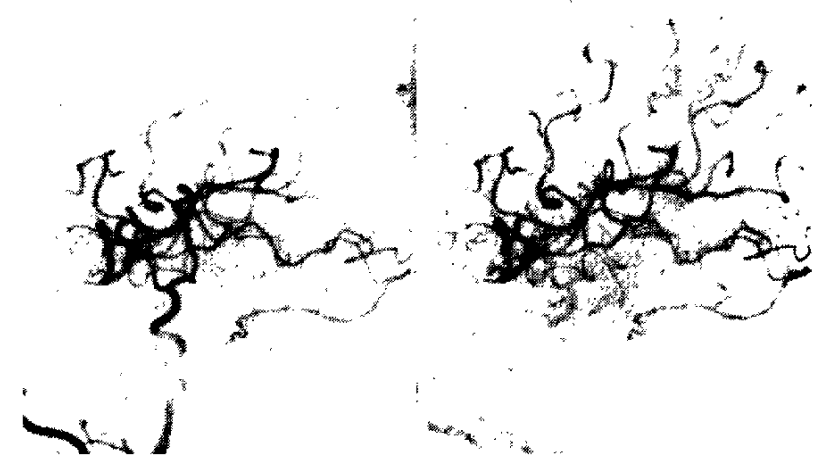

Fig. 9 Case 8; Postoperative right carotid angiogram showing good filling of the middle cerebral artery via the anastomosed superficial temporal artery. left; $2.0 \mathrm{sec}$ after injection, right; $2.5 \mathrm{sec}$ after injection.

artery (Fig. 8). A left carotid angiogram showed an aneurysm at the cavernous portion. Cerebral ischemic signs did not appear with Matas' test or EEG. Right internal carotid trapping was performed on April 9,1975 . The ophthalmic artery was coagulated at its origin and superficial temporal-middle cerebral artery anastomosis was performed. In addition, the left carotid-siphon aneurysm was treated by coating. The patient showed transient slight left-sided hemiparesis postoperatively; however, she did not show any neurological deficits after one week. The right carotid aneurysm was not visualized in the post-operative carotid angiogram, and the cortical branches of the middle cerebral artery were well filled through the anastomosed superficial temporal artery (Fig, 9).

\section{Coating}

Coating of the aneurysm was carried out on 6 carotidsiphon aneurysms (Table 4). In Cases 4, 5 and 7,

Table 4 Carotid-siphon aneurysms treated with coating

\begin{tabular}{|c|c|c|c|c|}
\hline $\begin{array}{l}\text { Case } \\
\text { No. }\end{array}$ & $\begin{array}{l}\text { Age } \\
\text { Sex }\end{array}$ & $\begin{array}{l}\text { Origin of } \\
\text { aneurysm }\end{array}$ & $\begin{array}{l}\text { Projection } \\
\text { of fundus }\end{array}$ & $\begin{array}{c}\text { Other aneurysm } \\
\text { or other } \\
\text { vascular diseases }\end{array}$ \\
\hline 4 & $\begin{array}{l}40 \\
M\end{array}$ & rt. $C_{3}$ & postero-medial & $\begin{array}{l}\text { rt. ICPC, lt. ICPC } \\
\text { lt. IC-Ant. chor. }\end{array}$ \\
\hline 5 & $\begin{array}{l}44 \\
M\end{array}$ & 1t. $\mathbf{C}_{3}$ & postero-medial & none \\
\hline 6 & $\begin{array}{l}38 \\
\mathrm{M}\end{array}$ & rt. $C_{2}$ & postero-medial & AVM \\
\hline 7 & $\begin{array}{l}21 \\
\mathbf{F}\end{array}$ & 1t. $\mathrm{C}_{3}$ & posterior & none \\
\hline 8 & $\begin{array}{c}65 \\
\mathrm{~F}\end{array}$ & It. $\mathrm{C}_{2}$ & superior & rt. IC-oph. \\
\hline 9 & $\begin{array}{c}46 \\
F\end{array}$ & rt. $\mathrm{C}_{2}$ & antero-medial & none \\
\hline
\end{tabular}

aneurysms at $C_{3}$ or $C_{4}$ of the carotid artery could only be exposed at the distal part, so they were only treated by coating through the inner surface of the dura mater. As Case 8 was treated by internal carotid artery trapping with superficial temporal-middle cerebral artery anastomosis for another carotidophthalmic aneurysm, the left carotid-siphon aneurysm was treated by coating to avoid stenosis of the internal carotid artery. In Cases $\mathbf{6}$ and 9, aneurysms projecting medially were only coated, because the optic nerve and distal portion of the internal carotid artery prevented approach. Case 9 was the only case of bleeding at the site of the carotid-siphon aneurysm.

\section{Discussion}

In Locksley's cooperative study, there were 143 carotidophthalmic aneurysms out of 2,672 intracranial aneurysms $(5.4 \%) ;{ }^{11)}$ Pool and Potts reported 2 of 15 aneurysms $(13 \%),{ }^{14)}$ and according to Jeanmart, intracavernous aneurysms account for $5 \%,{ }^{9}$, with the carotid-siphon aneurysm reported as a rare incidence. The authors experienced 20 carotid-siphon aneurysms out of 583 cases of intracranial aneurysms; a comparatively low incidence. Because of their anatomical locations, direct surgical approach is hazardous and difficult. Consequently, even given the low frequency of these aneurysms, there are a number of documents concerning their therapy, though often with poor operative results. Therefore various surgical treatments have been employed, including neck clipping, ${ }^{1,3,4,6,23)}$ common carotid ligation, ${ }^{8)}$ internal carotid trapping, and gradual carotid ligation. ${ }^{21)}$ However, the choice of operation depends on the location of the aneurysm, the projection of its fundus, and its anatomical relationship to the neighboring structures. The authors grouped the locations of carotid-siphon aneurysms and their fundi projections as seen by cerebral angiograms, for discussion of the surgical treatments accordingly.

\section{Aneurysms arising from the $\mathrm{C}_{2}$ portion}

The so-called carotid-ophthalmic aneurysms, are ordinally classified into the suboptico-chiasmal type, which project anteromedially, and the latero-chiasmal type, which project superoanteriory. In addition, Thurel added the global type ${ }^{19)}$ and there is also the paraophthalmic aneurysm with its posteromedial projecting sac, which Pia et al. ${ }^{13)}$ regarded as comparatively frequent. In many cases, the latero-chiasmal type of aneurysm can be clipped through the ipsilateral pterional approach without any damage to the optic nerve. However, the suboptico-chiasmal type is frequently more difficult to treat by the direct ap- 
proach $^{1,4,16,23)}$ because the optic nerve and distal portion of the internal carotid artery cover the aneurysm. Therefore, the ipsilateral optic nerve must be cut off in some cases so as to expose the internal carotid artery, the origin of the ophthalmic artery, and the aneurysm. ${ }^{1,3)}$ The authors had similar cases where the aneurysms projected medially. Such aneurysms were treated by coating because they could not be exposed completely through the ipsilateral pterional approach. However, such aneurysms, especially those of postero-medial projection, could be exposed and dissected from the internal carotid artery and the origin of the ophthalmic artery from the space between the bilateral optic nerves and the tuberculum sellae, through the contralateral pterional approach. This method was considered effective. Through the contralateral pterional approach, the authors could satisfactorily clip the neck of 3 carotid-siphon aneurysms projecting postero-medially without sacrificing the optic nerve. However, When the aneurysm is treated through the contralateral pterional approach, there must be a normo-or post-fixed chiasm with sufficient space between the optic chiasm and the tuberculum sellae. According to Shaefer's classification of the optic chiasm, a pre-fixed chiasm accounts for $5 \%{ }^{15)}$ In these cases, it is impossible to perform a direct attack through the contralateral pterional approach. Consequently, it is necessary to check the location of the optic chiasm before the operation. The authors checked its location by using metrizamide CT cisternography. ${ }^{12)}$

It is impossible to clip the neck of the large-sized aneurysm, when the internal carotid artery must be trapped. The authors prefer internal carotid trapping on large aneurysms, because it is unclear whether or not internal carotid ligation alone prevents hemorrhage. Such trapping is combined with superficialmiddle cerebral artery anastomosis to protect against cerebral ischemia. Using this method on 4 cases, no aneurysm was visualized in postoperative angiograms. Three of the cases are in excellent condition without neurological deficit. Therefore, the authors consider that this is an effective treatment of such large aneurysms. However, one patient died who required emergency internal carotid trapping because of aneurysm hemorrhage during the operation. The authors consider this type of emergency carotid trapping as having a poor prognosis, as Guidetti et al. reported. ${ }^{6}$

\section{Aneurysms arising from $\mathrm{C}_{3}$ or $\mathrm{C}_{4}$ portions}

These intracavernous portion aneurysms are effectively treated by internal carotid ligation with superficial temporal-middle cerebral artery anastomosis. The authors ligated the internal carotid artery on 2 aneurysms which were revealed very faintly in the postoperative angiograms, and whose middle cerebral artery was well filled via the anastomosed superficial temporal artery. Further, as compared with carotid-ophthalmic aneurysms which have about the same incidence of hemorrhage as other intracranial aneurysms, ${ }^{6,10)}$ the intracavernous portion aneurysm has a low possibility of intracranial hemorrhage and, can be safely treated with this method, as others have reported. ${ }^{10,20)}$ It is necessary to combining an EC.IC bypass with internal carotid ligation or trapping not only to prevent cerebral ischemia but also to prevent later development of aneurysms at other points. It is necessary to determine the resistance of the brain against cerebral ischemia with a preoperative Matas' test monitored by EEG and CBF. Cases where ischemia might be induced by internal carotid ligation should be treated with an EC IC bypass first, even though, according to Sundt et al. ${ }^{18)}$ the lower CBF limit is $30 \mathrm{~m} / / 100 \mathrm{~g}$ brain $/ \mathrm{min}$ in internal carotid ligation. The authors performed EC.IC bypasses on those cases where cerebral ischemia was shown to be possible. However, whether or not cerebral ischemia is prevented by the EC.IC bypass, monitoring of EEG and CBF is necessary during the operation. A definitive conclusion cannot be reached, however. The authors performed superficial temporal-middle cerebral artery anastomosis and internal carotid ligation or trapping at the same time on cases with such aneurysms, because there is otherwise a danger of hemorrhage with increasing blood pressure.

\section{References}

1) Almeida GM, Shibata MN, Bianco E: Carotidophthalmic aneurysms. Surg Neurol 5: 4-45, 1976

2) Anderson RD, Liebeskind A, Schechter MM, Zingesser LH: Aneurysms of the internal carotid artery in the carotid canal of the petrous temporal bone. Radiology 102: 639-642, 1972

3) Benedetti A, Curri D: Direct attack on carotidophthalmic and large internal carotid aneurysm. Surg Neurol 8: 49-54, 1977

4) Drake CG, Vanderlinden RG, Amacher AL: Carotid-ophthalmic aneurysms. I Neurosurg 29: 24-31, 1968

5) German WJ, Black SPW: Cervical ligation for internal carotid aneurysms. An extended follow up. $J$ Neurosurg 23: 572-577, 1965

6) Guidetti B, La Torre E: Management of carotidophthalmic aneurysms. $J$ Neurosurg 34: 544-548, 1971

7) Gurdjian ES, Linder DW, Thomas LW: Experiences with ligation of the common carotid artery for treatment of aneurysms of the internal carotid artery 
with particular reference to complications. $J$ Neurosurg 23: 311-318, 1965

8) Harrison TH, Odem GL, Kunkle EC: Internal carotid aneurysms arising in carotid canal. Arch Neurol 8: 328-331, 1963

9) Jeanmart L, Noterman J, Baleriaux D: Les anevrysmes des la carotide intracaverneuse. Neurochirurgie 19: $61-73,1973$

10) Kothandaran P, Dawson BH, Kruyt RC: Carotidophthalmic aneurysms: A study of 19 patients. $J$ Neurosurg 34: 544-548, 1971

11) Locksley HB: Report on the cooperative study of intracranial aneurysms and subarachnoid hemorrhage. Section V, Part I, Natural history of subarachnoid hemorrhage, intracranial aneurysms and AVM; based on 6,368 cases in the cooperative study. $J$ Neurosurg 25: 219-239, 1966

12) Mitsugi $T$, Kikuchi $H$, Karasawa $J$ : Metrizamide CT cisternography of optic chiasm. Progress in $C T$ 3: $551-555,1981$

13) Pia HW, Langmaid C, Zierski J: Cerebral Aneurysms, Advances in Diagnosis and Therapy. Berlin, SpringerVerlag, 1979, pp 67-82

14) Pool JL, Potts DC: Aneurysms and arterio-venous anomalies of the brain: Diagnosis and Treatment. New York, Harper \& Row, 1965, 463 pp

15) Schaefer JP: Some points in the regional anatomy of the optic pathway, with especial reference to tumors of the hypophysis cerebri; and resulting ocular changes. Anat Rec 28: 243-279, 1924
16) Sengupta RP, Gryspeerdt GL, Hankinson J: Carotidophthalmic aneurysms. I Neurol Neurosurg Psychiatry 39: 837-853, 1976

17) Spetzler RF, Schster H, Roski RA: Effective extracranial-intracranial arterial bypass in the treatment of inoperable giant aneurysm of the internal carotid artery. $J$ Neurosurg 53: 22-27, 1980

18) Sundt TM, Piepgras DG: Surgical approach to giant intracranial aneurysms. $J$ Neurosurg 51 : 731-742, 1979

19) Thurel C, Rey A, Thiebaut JB, Chai N, Houdart R: Anevrysmes carotido-ophthalmques. Neurochirurgie 20: 25-39, 1974

20) Tytus JS, Ward AA: The effect of cervical carotid ligation on giant intracranial aneurysms. $J$ Neurosurg 33: $184-190,1970$

21) Wemple JB, Smith GW: Extracranial carotid aneurysm. Report of four cases. $J$ Neurosurg 24: 667-671, 1966

22) Yasargil MG, Fox JL: The microsurgical approach to intracranial aneurysms. Surg Neurol 3: 7-14, 1975

23) Yasargil MG, Gasser JC, Hodosh RM, Rankin TV: Carotid-ophthalmic aneurysms: Direct microsurgical approach. Surg Neurol 8: 155-165, 1977

Request reprints to: T. Mitsugi, M.D., Department of Neurosurgery, National Center of Circulatory Disease, 5-125 Fujishirodai, Suita, Osaka 565, Japan. 